\title{
Beyond East and West - Geocommunicating Historical Sacred Landscapes
}

\author{
Markus Breier ${ }^{\mathrm{a}, *}$, Karel Kriz ${ }^{\mathrm{a}}$, Alexander Pucher ${ }^{\mathrm{a}}$, Lukas Neugebauer ${ }^{\mathrm{a}}$ \\ ${ }^{a}$ University of Vienna, markus.breier@univie.ac.at, karel.kriz@univie.ac.at, alexander.pucher@univie.ac.at, \\ lukas.neugebauer@univie.ac.at \\ * Corresponding author
}

\begin{abstract}
The Project "Beyond East and West: Geocommunicating the Sacred Landscapes of "Duklja" and "Raška" through Space and Time (11th-14th Cent.)" attempts to recreate and communicate the sacred landscape during a time of transition and transformation. The project has an interdisciplinary approach and incorporates multiple media, like maps, images, and 3D models. The study area of the project is situated at the junction between the Dinaric mountain range and the coastal region of the Adriatic Sea. Historically, the region was shaped by the power struggle between Byzantium, the First Bulgarian Empire, and the Serbian Realm. Ecclesiastically, it was a zone of interaction as well as encounter between Rome and Constantinople. The aim of the project is to discover and visualise the spatial and temporal aspects of these encounters and transformation processes.
\end{abstract}

To communicate the historical sacred landscape, a map-centred online application is used as a hub. To explore the relations between places, events, actors and artifacts, the users can follow the links between the entities. Content created during this project is more than points, lines or polygons which can be displayed on a map. Many objects are complemented with images, and for selected churches 3D models using aerial images captured by UAVs will be created. "Story Maps" are created for selected core research topics to provide an easily accessible starting point for users. The broader aim beyond the current research project is to provide a flexible framework, which can serve as a platform for similar research projects in historical geography and digital humanities.

Keywords: Thematic maps, digital humanities, geocommunication, historical geography

\section{Introduction}

The project Beyond East and West: Geocommunicating the Sacred Landscapes of "Duklja" and "Raška" through Space and Time (11th-14th Cent.)" (HOLDURA) ${ }^{1}$ and the corresponding application "Maps of Power: Historical Atlas of Places, Border Zones and Migration Dynamics in Byzantium (Dig-TIB)“ aims to recreate and communicate the sacred landscape in the regions "Duklja" and "Raška" during a time of transition and transformation. The project has an interdisciplinary digital/spatial humanities approach and incorporates multiple media, like maps, images, and 3D models.

The study area of the project is at the border regions of the present-day nations of Serbia, Montenegro, Kosovo, and Albania. The region is situated at the junction between the Dinaric mountain range and the coastal region of the Adriatic Sea. Historically, the region with the name Illyricum (Illyrikon) had an important strategic role in the Byzantine Empire (Koder 2017). The realms of "Duklja" and "Raška" were established during the medieval period. The region was shaped by the power struggle between Byzantium, the First Bulgarian Empire, and the Serbian Realm. Ecclesiastically, it was a zone of interaction as well as encounter between Rome and Constantinople, i.e. the Latin Church and the Byzantine Church.

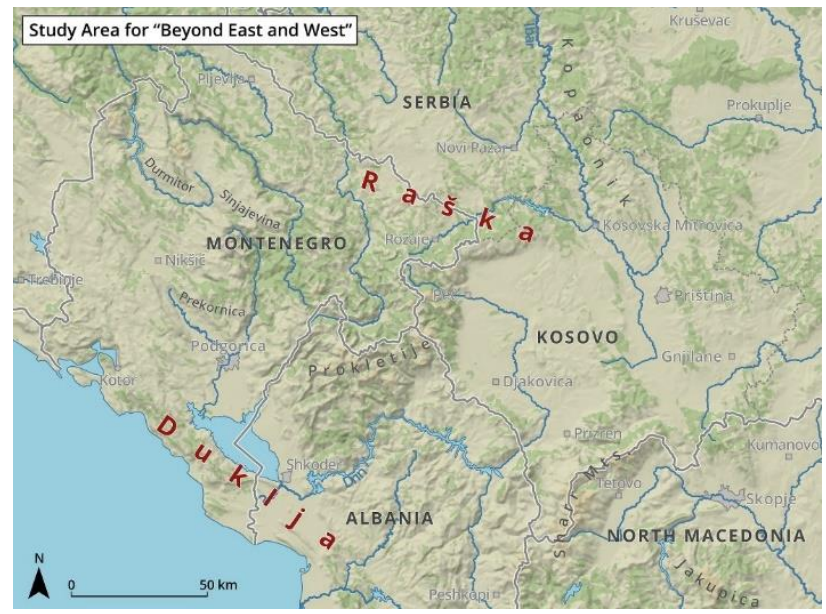

Figure 1. Study area

The project addresses the research question: in which way did the local rulers and the Churches of Rome and Constantinople interact in the region and how is this

\footnotetext{
${ }^{1}$ https://map.geo.univie.ac.at/sandbox/bew/index.html
} 
interaction mirrored in the distribution pattern of monuments (i.e. the churches and monasteries) in the scared landscape? The religious affiliation of the local rulers was fluctuating. This raises the issue of the impact of the changing affiliations: Were Latin or Byzantine places of worship transformed or superimposed in the course of time? Furthermore, it is of interest, if there was a strict separation between Latin West and Byzantine East, or if the landscapes should be perceived as a zone "Beyond East and West" (Dukljanin and Mosin 1950).

The aim of the project is to discover and visualise the spatial and temporal aspects of these encounters and transformation processes. In the project multiple scientific and scholarly disciplines as well as multiple institutions are involved: Byzantine Studies (Austrian Academy of Sciences), Art History (University Leipzig) and Cartography (University of Vienna).

\section{Aims and Methods}

The overarching research questions of the project are topics of historical geography. Digital cartography contributes to the gain of knowledge, in the line of digital and spatial humanities (Bodenhamer et al. 2010). From a cartographic point of view, the research aim is to create a multimedia representation and communication of the historical sacred landscape. To this aim, methods to communicate the different scale levels of historical landscapes will be explored. On the one hand, the project deals with single objects, like churches and monasteries, but also small objects of art. On the other hand, transregional processes and transformations are observed over a wide area. The interaction of these scale levels will be communicated in an efficient way.

There are two aspects to this undertaking: the representation and visualisation of objects and their locations should provide the historians with insights to decipher the historical landscape and to explore and analyse the spatial relations. The other aspect is the communication of both, the story behind the historical sacred landscape and the research results to the interested public outside the project.

Therefore, one of the primary goals of the cartography team is to communicate the complex content of the historical landscape in a way that is accessible to users not familiar with the underlying data structure. To communicate the historical sacred landscape, a mapcentred online application is used as a hub. This application enables the user to explore relevant places, events, actors, and artifacts and to show them on a map. Furthermore, the relations between these entities can be shown. All data is stored in an OpenAtlas database, a CIDOC-CRM compliant object-oriented database (Watzinger 2019).

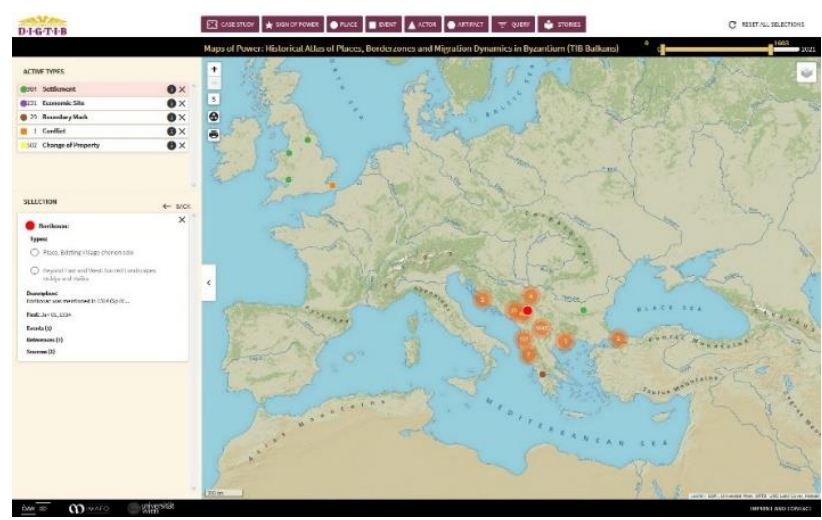

Figure 2. Screenshot of the application (as of August 2021)

To explore the relations between places, events, actors and artifacts, the users can follow links between the entities. For more complex queries which include multiple categories a query builder is available. This query builder reduces the complexity of the data structure to a more easily manageable degree. Using the query builder, it is possible to see, for example, which ruler donated which church, which person belonged to a religious group, or which persons had ties to a certain monastery.

The visualisation of places takes into account the certainty or uncertainty of its localisation. With many places taken from historical (i.e. written) sources, a precise and certain localisation is not possible. To represent this uncertainty, it is possible to create polygons in the database. These polygons represent possible locations for the corresponding place. It is also possible to define multiple possible areas for one place. To visualise the uncertainty, the application renders these polygons with fuzzy borders (Breier 2019).

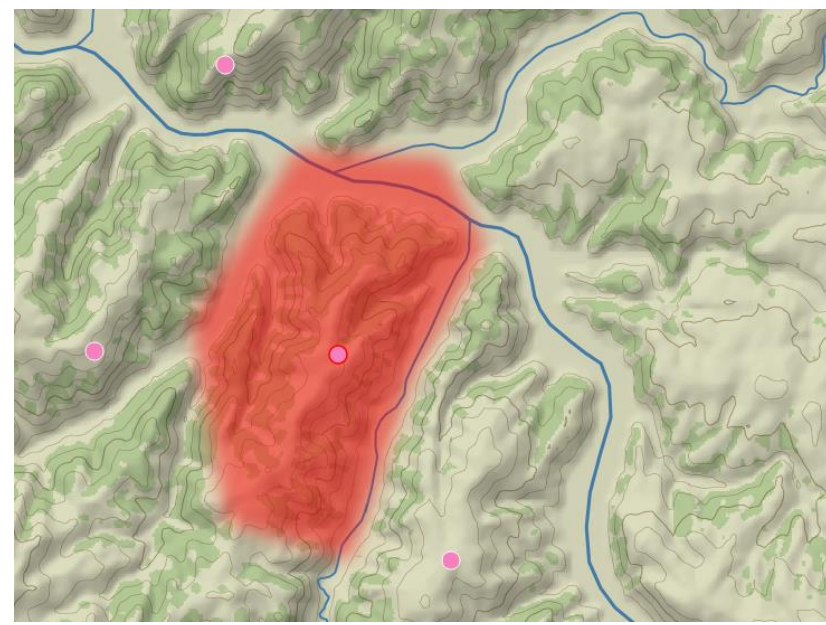

Figure 3. Uncertain location

Although interactive cartographic visualisation using points, lines, polygons is an important aspect, the project aims to bring the representation of the historical sacred landscape to the next level. To achieve this goal, a multimedia approach is used to go beyond classic cartographic visualisation methods. 
In the database, many objects have images attached. These images are displayed when an object is selected and they also illustrate some visual details of the places. They additionally serve to provide details relevant for an art historical classification. With persons (i.e. actors), portraits are linked, if available.

Furthermore, 3D models of selected churches and church ruins will be created. This visualisation enables the user to explore spatial structures on a very large scale. Historicgeographic aspects in building structures of churches, which are inadequately discernible with static images, emerge from interactive 3D models. Such 3D models offer new possibilities to experience space, thus providing important means of geocommunication. The information necessary to create these detailed $3 \mathrm{D}$ models will be gathered by consumer-grade UAVs. The UAV takes a great number of images of an object. With Structure-fromMotion and photogrammetry (Westoby et al. 2012), these images are positioned in space and transformed into georeferenced 3D models. These models can be rotated and zoomed.

The project is part of the long-term project researching the historical geography of the Byzantine Empire, "Tabula Imperii Byzantini (TIB)" of the Austrian Academy of Sciences. During this project, printed maps of the Byzantine provinces were created. These and some relevant historical maps were georeferenced and were integrated into the application. They can be superimposed at the correct extent in the application. This is also true for further maps created during this and associated projects. In this way, the application serves as an access point to a map archive.

To provide an easy access for non-expert users, selected research topics are prepared as "Story Maps". "Story Maps" consist of pre-defined historic-geographic content, which is complemented with additional images and explanatory text. The stories are created by the historians and give insight into special research aspects. They are structured in chapters or steps. Each chapter has a defined map view with a set of data to highlight the spatial aspect. To communicate the topic in an engaging manner, images and text provide context and interpretation. The "Story Maps" are an independent module, which does not require the user to be familiar with the data structure or which data is in the database.

\section{Current Status}

The project started in March 2020 and runs until the end of February 2023. The development of the application started during a previous project, „Digitizing Patterns of Power - Peripherical Mountains in the Medieval World (DPP)“ (Breier et al. 2020; Eichert et al. 2016). It is expanded in functionality and enhanced in performance and usability. At the time of writing, the user interface is reworked.

In fall 2020, a test run was undertaken to test the creation of 3D models. The test was done on Castle Ebreichsdorf, south of Vienna. During the test run, critical parameters were identified. The exposure of the images must not contain clipped brightness values (over- or underexposure), because the method cannot reconstruct correct 3D structures in clipped areas.

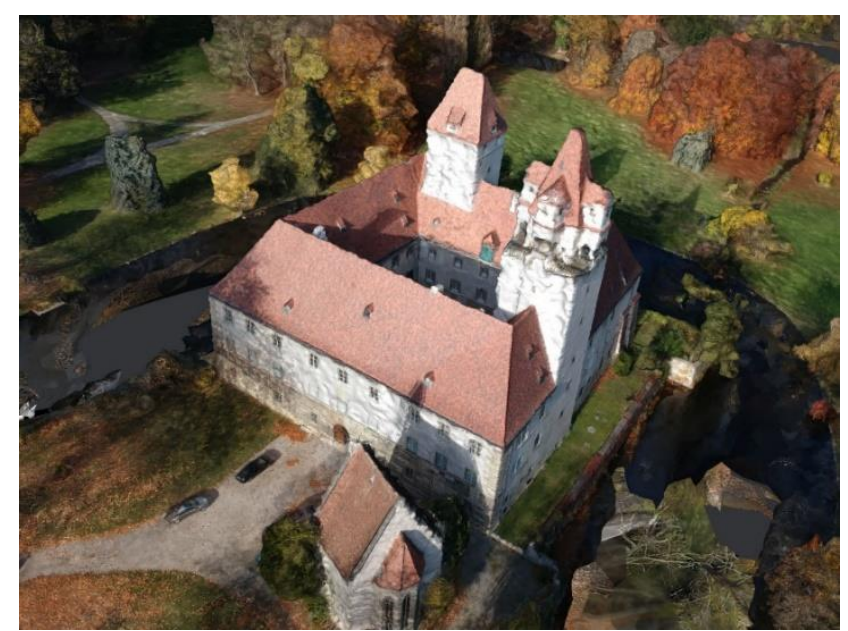

Figure 4. First test Structure-from-Motion (Castle Ebreichsdorf, Austria)

In fall 2021, a field trip to Montenegro is planned to capture the aerial images for the 3D models. Selected churches will be visited, and a consumer-grade UAV will be used to capture the images. Subsequently, the 3D models will be created. The amount of data for a 3D model is quite large. Therefore, the $3 \mathrm{D}$ models must be integrated into the application in a way that allows for fast data transfer to provide an uncompromised user-experience. Tests to find an ideal solution to this issue are underway.

Currently, various stand-alone maps are created for selected topics. The user-experience of the application and the project web page is undergoing an optimization process. The web presence of the project is redesigned following up-to-date web design philosophies. The web page will contain a narrative to guide the visitor through the various aspects of the project. The web page is an essential part of the geocommunication strategy of the project and enables a visitor to experience the project and the historical sacred landscape.

\section{Outlook}

The broader aim beyond the current research project is to provide a flexible framework, which can serve as a platform for similar research projects in historical geography and digital humanities. The project HOLDURA is a project which started out with a core vision, but as the project progresses, various new ideas are integrated, as one aspect triggers another aspect of communication.

"Story Maps" are an important aspect of geocommunicating the landscape and one of the most important content modules of the application. Therefore, it is important for "Story Maps" to be easily created and edited. To facilitate this, a simple GUI based editor is planned. This tool will not be available to the users but will 
be a tool for the scholars in the project to simply add content.

At the moment the interactive map-based online application is the entry point to the reconstruction and communication of the historical sacred landscape. Due to the complexity of the database and minimal user guidance, the application is not very accessible to users outside the project team. The application has highly intuitive usability, nonetheless a more stringent storytelling and user guidance would improve user-experience. This will be done by creating a starting portal, which is used to tell the story of the project, and thus guiding the user through the historical landscape and the research results.

The various aspects of the project as well as the various data types should be integrated in a way to provide consistent and seamless user-experience. This is equally true for the project partners, using the application to analyse and visualise their data, as well as for the interested visitor, who want to experience the historical landscape. Accompanying the historical research, further "Story Maps" will be created. They will be created in cooperation with Byzantinists and Art Historians. Alongside scholarly publications, "Story Maps" are the medium by which research questions and results are communicated to the public. Thus, they are an important part of the project's output.

Until the end of the project, the platform will undergo some development stages and will gain additional functionality. The query builder, for example, should be able to facilitate more complex queries, without getting more complicated to use. More filters will be implemented, as well as connections to other services, like the projects Pelagios ${ }^{2}$ and Recogito ${ }^{3}$.

Thanks to the modular design of the technical framework, the application is easily adaptable to other, similar projects. That encompasses geographical as well as functional extensions. The application itself as well as the OpenAtlas database are built on Open-Source technology. Therefore, both sub-systems can be adapted to the requirements of different projects in the realm of spatial/digital humanities.

\section{Conclusion}

The project „Beyond East and West: Geocommunicating the Sacred Landscapes of "Duklja" and "Raška" through Space and Time (11th-14th Cent.)" (HOLDURA) and the corresponding application "Maps of Power: Historical Atlas of Places, Border Zones and Migration Dynamics in Byzantium (Dig-TIB)“ are comprehensive tools for the exploration and communication of the historical sacred landscape in the Western Balkan. In the sense of "digital humanities", digital cartographic methods are used and adapted to the questions in order to help in the reconstruction of historical conditions and processes. The methods used to represent the spatio-temporal aspect are not limited to classical cartographic representations. On the one hand, data on places, events and actors are retrieved from a database. The object-oriented database also contains the relationships of these objects to each other. These relationships can also be followed in the application. Although the database is of high complexity, the application allows intuitive access to the data. For users who do not want to or cannot deal with the data structure, the system provides access via the "story maps" and via a website that presents a narrative of the historical landscape. In addition, the project also serves as a feasibility study in terms of large-scale $3 \mathrm{D}$ visualizations of individual landscape elements. For example, selected churches will be scanned as 3D models using structurefrom-motion techniques. Although this can only be done for a few selected churches within the scope of the project, such methods can provide an additional layer of information and narrative.

In the field of geocommunication the visual and technical implementation of spatial structures and their relations over various scales is a challenge. The gradual spatial experience possible from small-scale maps to large-scale 3D models requires a multimedia presentation form to provide efficient geocommunication. Small scale maps are used to locate objects and explore their interrelationships in the region. Large scale models make small structures recognizable.

The framework for the data structure and visualizations is modularly built on open standards and therefore flexible. It is therefore future-proof and together with the knowhow acquired through this and previous projects it can also serve as a basis for future projects in the field of spatial humanities.

\section{Acknowledgements}

The authors like to thank Mihailo St. Popovic. He is the primary investigator for the project HOLDURA at the Austrian Academy of Sciences, Institute for Medieval Research. He provides support and assistance regarding historical topics and research questions.

\section{References}

Bodenhamer DJ, Corrigan J, Harris TM (eds) (2010) The spatial humanities: GIS and the future of humanities scholarship. Spatial humanities. Indiana University Press, Bloomington

Breier M (2019) Representing Spatial Uncertainty of Historical Places and Space in Interactive Maps. In: Popović M, Polloczek V, Eichert S, Koschicek B (eds) Power in Landscape - Geographic and Digital Approaches in Historical Research, vol 2. Eudora Verlag, Leipzig, pp 165-179

Breier M, Mertel A, Kriz K, Pucher A (2020) Digitising Patterns of Power: An Interactive Map-Based Application to Represent Historical Landscapes. In:

${ }^{2}$ https://pelagios.org/ <accessed 16/08/2021>

${ }^{3}$ https://recogito.pelagios.org/ <accessed 16/08/2021> 
Ernst M, Hinklemanns P, Zangerl LM, ZeppezauerWachauer K (eds) Digital Humanities Austria 2018. Empowering Researchers. Austrian Academy of Sciences Press, Vienna, pp 21-28

Dukljanin, Mosin V (1950) Ljetopis popa Dukljanina: Latinski tekst sa hrvatskim prijevodom i "Hrvatska kronika". (Priredio, napisao uvod i komentar Vladimir Mosin.). Latinski tekst sa hrvatskim prijevodom i "Hrvatska kronika". Matica Hrvatska, Zagreb

Eichert S, Koschicek B, Popović M (2016) Digitising Patterns of Power (DPP): A Digital Approach towards Recording, Managing, Analysing and Presenting Archeological and Historical Information based on Case Studies from Eurasian Mountainous Regions. Acta Archaeologica Carpathica:257-283

Koder J (2017) Illyrikon und Illyrios: Prosopon Rhomaikon. In: Beihammer AD, Krönung B, Ludwig C (eds) Prosopon Rhomaikon: Ergänzende Studien zur Prosopographie der mittelbyzantinischen Zeit. De Gruyter, Berlin, Boston, pp 197-210

Watzinger A (2019) OpenAtlas - How to Grow Software for Historians. In: Popović M, Polloczek V, Eichert S, Koschicek B (eds) Power in Landscape - Geographic and Digital Approaches in Historical Research. Eudora Verlag, Leipzig, pp 193-201

Westoby MJ, Brasington J, Glasser NF, Hambrey MJ, Reynolds JM (2012) 'Structure-from-Motion' photogrammetry: A low-cost, effective tool for geoscience applications. Geomorphology 179:300-314. https://doi.org/10.1016/j.geomorph.2012.08.021 